\title{
Predictors of long-term smoking cessation in patients with COPD: results from a randomised controlled trial
}

To the Editor:

In Western countries, cigarette smoking is the most important risk factor for the development of chronic obstructive pulmonary disease (COPD) [1]. Besides, patients with COPD who continue to smoke have a higher prevalence of respiratory symptoms, more accelerated decline in lung function and higher mortality rate than nonsmokers [1]. Therefore, smoking cessation is the single most effective way to prevent COPD and reduce its progression [1]. The Cochrane Review on smoking cessation interventions for people with COPD shows that evidence-based smoking cessation interventions exist, but the chances of successful quitting are still relatively low in this group of smokers [2]. The effectiveness of such interventions can depend on the characteristics of the patient [3]. Knowing which patient characteristics are associated with successful quitting might facilitate the design of more effective smoking cessation interventions for patients with COPD.

We used data from a randomised controlled smoking cessation trial to identify patient-specific predictors for long-term abstinence. This trial was originally designed to assess the efficacy of confronting smokers with newly found airflow limitation to facilitate smoking cessation (ISRCTN 64481813) [4]. A total of 296 smokers with mild-to-moderate COPD were randomly allocated to confrontational counselling with a nurse and administered nortriptyline for smoking cessation (experimental group), regular counselling with a nurse and nortriptyline (control group 1), or "care as usual" for smoking cessation by their general practitioner (control group 2) [4,5]. Inclusion criteria were as follows: a smoking history of $\geqslant 10$ pack-years; competency in reading and speaking Dutch; reporting of at least one respiratory symptom (cough, sputum production, or shortness of breath); and a post-bronchodilator forced expiratory volume in one second $(\mathrm{FEV} 1) /$ forced vital capacity $(\mathrm{FVC})<70 \%$ in combination with post-bronchodilator $\mathrm{FEV} 1$ $>50 \%$ predicted $[1,6]$. Exclusion criteria were as follows: having contraindications for the use of nortriptyline; prior respiratory diagnosis; and having undergone spirometry during the preceding 12 months $[4,5]$.

The primary outcome for the current analysis was cotinine-validated prolonged abstinence from smoking from weeks 5-52 after the target quit date, as defined in the original trial [4]. From all data collected during baseline measurements of the trial (i.e. prior to randomisation), we selected candidate predictors of abstinence based on theory and existing evidence; we selected various demographic, health and smoking characteristics, as well as those of social influence. Seventy-five participants had one or more missing values, which we imputed by using multiple imputation techniques. We entered 21 predictor variables into the initial logistic regression model and adjusted the model for group allocation (even though abstinence rates did not differ significantly between groups [4]). We then used manual backward elimination $(\mathrm{p}<0.02)$ to determine the best-fit model.

After 52 weeks, 30 of the 296 participants (10\%) were still abstinent and 266 participants (90\%) had relapsed to smoking (table 1; the 21 variables from the initial model are indicated with an asterisk). After manual backward elimination, three variables remained significant predictors of abstinence. The odds of abstinence were: 3.23 times higher in participants with a high level of education than in participants with a low level of education (95\% CI 1.03-10.15); 1.03 times higher per point increase in general health

@ERSpublications

Attention to patients' health perceptions and social environment is important for successful quitting http://ow.ly/cPn630b3z1r

Cite this article as: van Eerd EAM, van Schayck OCP, Wesseling G, et al. Predictors of long-term smoking cessation in patients with COPD: results from a randomised controlled trial. Eur Respir J 2017; 49: 1700561 [https://doi.org/10.1183/13993003.00561-2017]. 
TABLE 1 Baseline characteristics of study participants who were abstinent from weeks 5-52 and those who relapsed to smoking

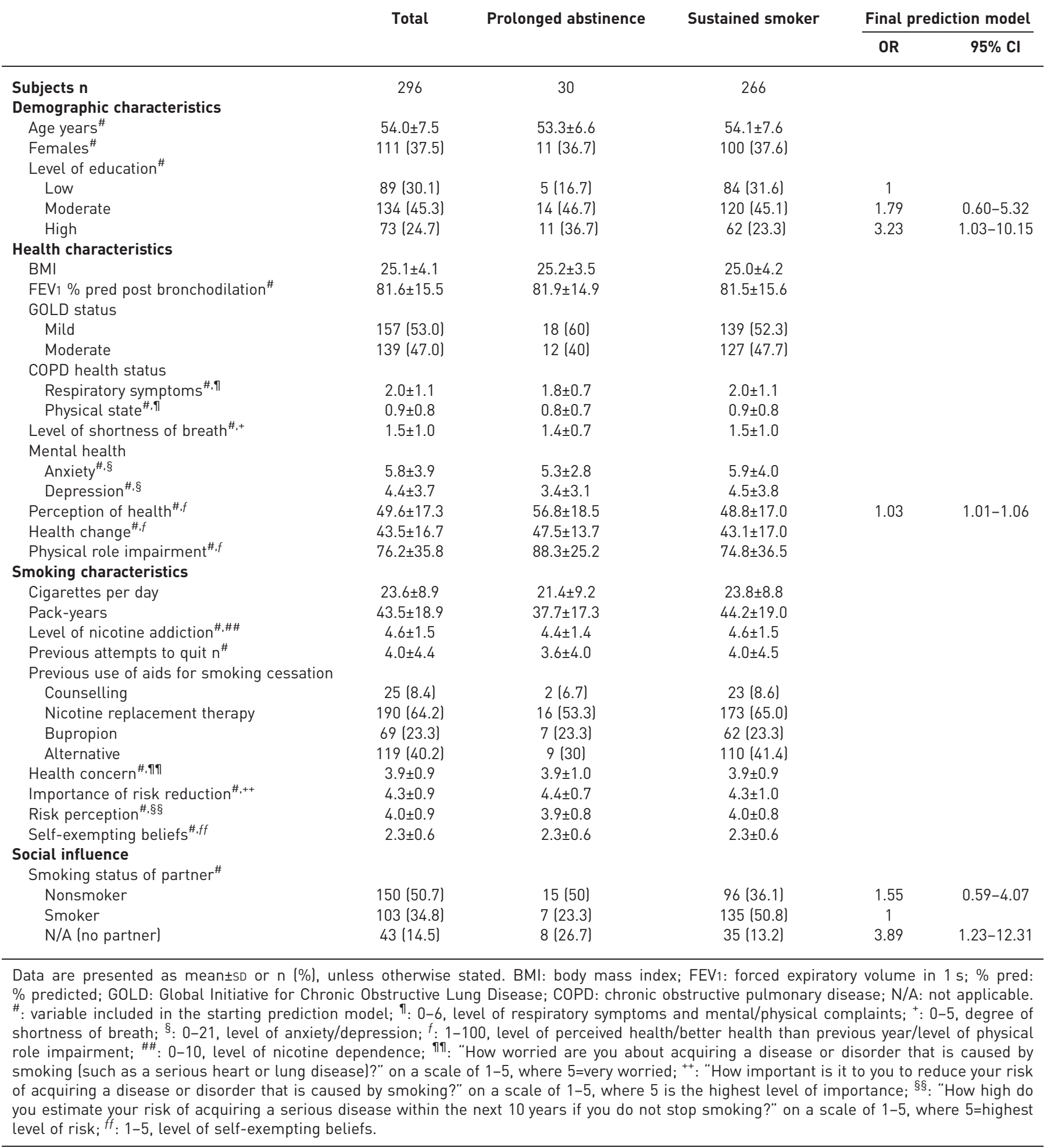

perception (scale 1-100, 95\% CI 1.01-1.06); and 3.89 times higher in participants without a partner compared to smokers with a partner who also smoked (95\% CI 1.23-12.31).

Our findings suggest firstly that smokers with COPD and a low level of education are much less likely to quit smoking successfully. This social gradient has been reported previously in the general smoking 
population [7] and in smokers with COPD [8], and might be explained by the influence of the social environment [9], higher levels of nicotine dependence [10] and psychological distress in more disadvantaged smokers $[9,11]$.

Secondly, smokers with COPD and better self-perceived general health seemed to be more likely to quit smoking successfully. A previous study showed that when one's health deteriorates, based on the Global Initiative for Chronic Obstructive Lung Disease (GOLD) A-D criteria, the motivation for quitting increases [8]. We are not aware of any other studies that use subjective health measures and can only speculate that in our study, the perception of better health might have been associated with stronger self-efficacy to refrain from smoking, resulting in more successful attempts to quit.

Thirdly, when comparing the baseline characteristics of successful and unsuccessful quitters, the latter seemed more likely to have a partner who also smoked. In the final prediction model, not having a partner at all predicted abstinence. Unfortunately, we were unable to confirm whether these participants were indeed living without a partner. Therefore, these results should be interpreted with caution.

In our study, nicotine dependence was not associated with abstinence, possibly because the participants were selected using very strict criteria, resulting in a very homogeneous group of heavy smokers.

Finally, psychological distress, including depressive symptoms, might contribute to the unsuccessful attempts of smokers to quit [11-14]. The chances of having depressive symptoms are high in patients with COPD, regardless of their smoking status [15]. All participants of the present study had a low level of depressive symptoms. The main reason for this finding was probably the exclusion of smokers who used antidepressants [4]. However, smokers that relapsed seemed to report a greater number of depressive symptoms at baseline than those who successfully quit. Nevertheless, no significant differences emerged from the prediction model.

We excluded smokers who took antidepressants and those with previously undetected severe airflow limitation, thereby limiting the external validity of our findings. The controlled circumstances of the trial, on the other hand, can be seen as a strength, as the risk of confounding was reduced. The sample size $(\mathrm{n}=296)$ for the current analysis limited the statistical power to determine significant predictors. We observed differences in baseline characteristics between those who became abstinent and those who relapsed; however, these characteristics did not emerge as predictors of successful quitting in the final model. We combined the three intervention groups to obtain a more substantial group size to predict successful quitting. We included "group allocation" as a variable in the model to correct for any effects of the different interventions on long-term abstinence. Unfortunately, the sample size was too small to further correct for this by including interaction terms in the model or conducting sensitivity analyses for the three intervention groups separately.

In conclusion, COPD patients with a high level of education, more favourable general health perception and those living without a partner, appeared to be more likely to successfully quit smoking in the long term. Healthcare providers should take the health perceptions and social environments of patients into account to facilitate successful quitting in COPD patients.

Eva A.M. van Eerd ${ }^{1}$, Onno C.P. van Schayck ${ }^{1}$, Geertjan Wesseling ${ }^{2}$ and Daniel Kotz ${ }^{1,3}$

${ }^{1}$ Dept of Family Medicine, Maastricht University Medical Centre, CAPHRI Care and Public Health Research Institute, Maastricht, The Netherlands. ${ }^{2}$ Dept of Respiratory Medicine, Maastricht University Medical Centre, CAPHRI Care and Public Health Research Institute, Maastricht, The Netherlands. ${ }^{3}$ Addiction Research and Clinical Epidemiology Unit, Institute of General Practice, Heinrich-Heine-University Düsseldorf, Düsseldorf, Germany.

Correspondence: Eva A.M. van Eerd, P.O. Box 616, 6200 MD Maastricht, The Netherlands.

E-mail: eva.vaneerd@maastrichtuniversity.nl

Received: Feb 152017 | Accepted after revision: March 172017

Conflict of interest: Disclosures can be found alongside this article at erj.ersjournals.com

\section{References}

1 Global Initiative for Chronic Obstructive Lung Disease. Global Strategy for the Diagnosis, Management and Prevention of COPD. http://goldcopd.org Date last updated: February 1, 2017. Date last accessed: November 17, 2015.

2 van Eerd EA, van der Meer RM, van Schayck OC, et al. Smoking cessation for people with chronic obstructive pulmonary disease. Cochrane Database Syst Rev 2016; 8: CD010744.

3 US Department of Health and Human Services. Public Health Service. Clinical practice guideline. Treating tobacco use and dependence: 2008 update. www.ncbi.nlm.nih.gov/books/NBK63952/. Date last updated: February 1, 2017. Date last accessed: November 17, 2015.

4 Kotz D, Wesseling G, Huibers MJ, et al. Efficacy of confronting smokers with airflow limitation for smoking cessation. Eur Respir J 2009; 33: 754-762. 
5 Kotz D, Wesseling G, Huibers MJ, et al. Efficacy of confrontational counselling for smoking cessation in smokers with previously undiagnosed mild to moderate airflow limitation: study protocol of a randomized controlled trial. BMC Public Health 2007; 7: 332.

6 Cigarette smoking and health. American Thoracic Society. Am J Respir Crit Care Med 1996; 153: 861-865.

7 Kotz D, West R. Explaining the social gradient in smoking cessation: it's not in the trying, but in the succeeding. Tob Control 2009; 18: 43-46.

8 Tottenborg SS, Thomsen RW, Johnsen SP, et al. Determinants of smoking cessation in patients with COPD treated in the outpatient setting. Chest 2016; 150: 554-562.

9 Wiltshire S, Bancroft A, Parry O, et al. 'I came back here and started smoking again': perceptions and experiences of quitting among disadvantaged smokers. Health Educ Res 2003; 18: 292-303.

10 Jarvis MJ, Wardle J, Waller J, et al. Prevalence of hardcore smoking in England, and associated attitudes and beliefs: cross sectional study. BMJ 2003; 326: 1061.

11 Siahpush M, Carlin JB. Financial stress, smoking cessation and relapse: results from a prospective study of an Australian national sample. Addiction 2006; 101: 121-127.

12 Adams SG, Pugh JA, Kazis LE, et al. Characteristics associated with sustained abstinence from smoking among patients with COPD. Am J Med 2006; 119: 441-447.

13 Kupiainen H, Kinnula VL, Lindqvist A, et al. Successful smoking cessation in COPD: association with comorbidities and mortality. Pulm Med 2012; 2012: 725024.

14 Glassman AH, Helzer JE, Covey LS, et al. Smoking, smoking cessation, and major depression. JAMA 1990; 264 1546-1549.

15 Mannino DM, Buist AS. Global burden of COPD: risk factors, prevalence, and future trends. Lancet 2007; 370: 765-773. 